\title{
Alemania, México y los Estados Unidos durante la Segunda Guerra Mundial*
}

Friedrich Schuler

La relación triangular entre Alemania, México y los Estados Unidos durante la Segunda Guerra Mundial no ha sido investigada ni en la literatura alemana ni en la norteamericana o mexicana. Sin embargo, esta relación merece especial atención porque difiere en varios aspectos de la pauta normal de las relaciones euro-latinoamericano-estadunidenses.

En primer lugar, estratégicamente, la proximidad mexicana a los Estados Unidos era de especial interés para el gobierno alemán, con miras a influir en la política de defensa hemisférica del hemisferio occidental.

Económicamente, las relaciones germano-mexicanas de 1933 a 1940 diferian de las típicas relaciones económicas germano-latinoamericanas. México había guardado de manera persistente una distancia económica y siempre se había rehusado a establecer un convenio económico bilateral con la Alemania nazi, como el que habian hecho en 1934 otras naciones sudamericanas con el recién establecido Tercer Reich.' Además, las modestas ganancias económicas obtenidas por Alemania hasta 1938 en el mercado mexicano, no se hicieron a expensas de la cuota comercial de los Estados Unidos. Por lo tanto, la economia alemana no competía directamente con la de los Estados Unidos, sino que ambos países ampliaban su posición en el mercado a expensas del comercio británico.

Sin embargo, esto cambió rápidamente en 1938, después de la nacionalización en México de las compañías petroleras extranjeras, cuando este país empezó a intercambiar petróleo por productos alemanes manufacturados. Alemania adquiría en 1939 casi los $2 / 3$ de todo el petróleo mexicano exportado. ${ }^{2}$ Ello cobró especial importancia debido a la creciente tensión existente entre la Alemania nazi y los Estados Unidos. Cualquier país fuera del hemisferio occidental que ejerciera una influencia tan crucial en México era una provocación a la Doctrina Monroe, a la hegemonía de los Estados Unidos en América Latina y a su política exterior del "Buen Vecino". ${ }^{3}$ En 1938, el embajador alemán en los Estados Unidos había manifestado lo siguiente:

* Artículo publicado en Jahrbuch für Geschichte von Staat, Wirtschaft und Gesellschaft Latein-amerikas. Traducción de Alicia Bergua.

Hans Jürgen Schröeder, "Die'neuc deutsche Südamerika-Politik." Dokumente zur nationalsozialistischen Wirtschaftspolitik in Lateinamerika von 1934-1936, en Jahrbuch für Geschichte von Staat, Wirtschaft und Gesellschaft Lateinamerikas, 1969, vol. 6, p. 337-346.

Anuario Estadístico de los Estados Mexicanos 1939, México, Secretaría de Economia Nacional, Dirección General de Estadística, 1941, p. 596.

${ }^{3}$ Merill Rippy, Oil and the Mexican Revolution, Leiden, 1972, p. 120. 
El interés de los Estados Unidos es y será la continuidad y el mantenimiento del mercado libre internacional, tanto como sea posible. Así Washington tendrá inevitablemente que detener el avance de los estados totalitarios hacia una posición de poder. ${ }^{4}$

El tercer interesado en este triángulo era el propio México. Tradicionalmente Alemania habia actuado como suplente en la economia mexicana cuando era oportuno. Por ejemplo, los comerciantes alemanes se hicieron cargo de la importación y exportación de un importante sector económico de artículos después de la intervención europea de la década de 1870 en México. Los banqueros alemanes proporcionaron créditos al gobierno de Díaz permitiéndole financiar la nacionalización del sistema mexicano del ferrocarril. ${ }^{5}$ En consecuencia, los gobiernos mexicanos siempre habían usado los intereses alemanes para suplir los intereses británicos o estadunidenses, en un intento de ganar mayor independencia respecto de estos dos países y de sus intereses económicos. Ya durante la primera guerra mundial, un gobierno alemán había intentado explotar este interés mexicano para sus propios fines, como lo manifiesta el despacho Zimmermann.

La literatura existente se ha concretado siempre a tratar las relaciones bilaterales entre los Estados Unidos y México. Incluso, como principal fuente para la discusión académica sobre México y los Estados Unidos durante la segunda guerra mundial, se han usado libros escritos por periodistas en la década de 1940, que se extendian acerca de la candente atmósfera mexicana antes de las elecciones de ese mismo año. ${ }^{6}$ Estos periodistas trabajaban bajo el supuesto de la buena vecindad entre los Estados Unidos y México y de su pretendido interés común en la lucha contra los intereses del Eje en México.?

Este artículo intenta mostrar el desarrollo de las relaciones triangulares entre los Estados Unidos, México y el Tercer Reich, basándose ampliamente en fuentes primarias del Ministerio de Asuntos Extranjeros alemán y en los despachos de la legación alemana en la ciudad de México. Se examinan las relaciones políticas y económicas dentro de este triángulo, las pretendidas actividades de la Quinta Columna en México y se describe la política del "Buen Vecino" entre México y los Estados Unidos, desde el punto de vista alemán.

En el verano de 1939, los jefes de las legaciones y embajadas alemanas en América Latina se reunieron para una conferencia en Berlín. Ahí, el embajador alemán en México, el barón Rüdt von Collemberg dio a conocer su opinión acerca de las relaciones existentes entre México y Alemania y sobre su futuro.

El ministro Rüdt describió el desarrollo de la política interna en México como positivo para los intereses alemanes. Acogió con sa-

4 Akten zur Deutschen Auswärtigen Politik (1937-1945), Baden-Baden, 1953, Thomsen a Auswärtiges Amt (AA), p. 594 y ss.

${ }^{5}$ Friedrich Katz, The Secret War in Mexico, Europe, the United States and the Mexican Revolution, Chicago y Londres, 1981, p. 50-119.

${ }^{6}$ Betty Kirk, Covering the Mexican Front, Norman, 1942; Virginia Prewet, Reportage on Mexico, Nueva York, 1941; Sylvia y Nathaniel Weyl, The Reconquest of. Mexico, Londres, 1939.

${ }^{7}$ Edward O. Guerrant, Roosevelt's Good Neighbor Policy, Albuquerque, 1950. 
tisfacción la inclinación del gobierno mexicano hacia políticas de derecha y el aparente fin del flirteo con la izquierda, con sus ideas y con su retórica. Según Rüdt, la prensa mexicana se había hecho más receptiva a las opiniones del Tercer Reich sobre el rechazo al Tratado de Versalles y la anexión de Austria y Checoslovaquia a Alemania. Esta observación se apoyaba en el comportamiento del secretario de Relaciones Exteriores mexicano al aceptar sin protesta la ocupación alemana de la legación y consulados de Checoslovaquia y Austria en México. Además, según señaló Rüdt, las instituciones alemanas y las organizaciones de la comunidad mexicano-alemana parecían no estar ya en peligro por las actividades socialistas o comunistas de la izquierda mexicana.

En el futuro, México podría tener interés en mantener buenas relaciones con Alemania, principalmente en relación a los asuntos económicos. Por lo tanto, consideraba que la tarea predominante de la política alemana era la de establecer un tratado general de comercio bilateral con México. Esto podria mantener unidos a México y Alemania por un periodo más largo y al mismo tiempo aumentar la distancia entre los Estados Unidos y México. En opinión de Rüdt, no se vislumbraba el fin, en un futuro cercano, de la disputa petrolera México-Estados Unidos. Por lo que, en tiempo de paz, México podría recurrir a los Estados Unidos solamente en una crisis económica o financiera seria. En ese caso los Estados Unidos podrían ofrecer a México concesiones económicas inmediatas y comprar su cooperación con asistencia financiera. Un tratado económico bilateral germano-mexicano ayudaría a evitar esta cooperación mexicano-estadunidense. Sin embargo, debido a la proximidad de los Estados Unidos, Alemania no debería esperar del gobierno mexicano una actitud progermana abierta. Asimismo, México evitaría en el futuro cualquier acción que pudiera interpretarse como antiestadunidense o en contra del hemisferio occidental.

En el caso de que Alemania se involucrara en una guerra, Rüdt predecia que el Tercer Reich no contaria con el apoyo mexicano o con su neutralidad. Antes bien México apoyaria al enemigo donde encontraría mayores ventajas económicas.

En resumen, Rüdt veía la relación económica entre México y Alemania como de la mayor importancia para el futuro. Es más, el antiamericanismo existente en la sociedad y el gobierno mexicanos tenia un papel crucial en los objetivos germanos. Insistía en usar las fricciones existentes para mantener a México alejado de los Estados Unidos y, en consecuencia, comprometer la política estadunidense del "Buen Vecino" y debilitar al hemisferio occidental. ${ }^{8}$

Sólo tres meses después de esta conferencia comenzaba la segunda guerra mundial. En contra de las predicciones de Rüdt, México se declaró neutral. Luego, la siguiente Conferencia de La Habana no produjo efectos dañinos para los intereses económicos

\footnotetext{
* "Protokoll der Lateinamerika-Konferenz de 12 de junio de 1939, Rüdt, en Records of the German Foreign Ministry Archives (1920-1945), US National Archives. microfilm núm. 257/168723821 Head of Auslandsorganisationen Ibero America/Racial Laws.
} 
germanos en América Latina y México, ${ }^{9}$ por lo que el ministro alemán de Economía planteó continuar el comercio con América Latina por medio de embarcaciones neutrales y a través de puertos europeos, burlando así el bloqueo británico.

Aunque las condiciones externas concernientes al comercio no fueron demasiado negativas después de la Conferencia de $\mathrm{Pa}$ namá, las relaciones económicas germano-mexicanas sufrieron retroceso tras retroceso desde el estallido de la guerra. Los problemas surgieron en el Tercer Reich y en sus cuestiones económicas.

Inmediatamente después de estallar la guerra, las compañías germanas afectadas cancelaron sus contratos con los contratistas mexicanos, principalmente para renegociar las formas de pago, cambiando las operaciones de trueque por pago en efectivo. ${ }^{6} \mathrm{De}$ bido al hecho de que las entregas alemanas a México se reembolsaban con embarques de petróleo, estas cancelaciones involucraron al Ministerio de Economía alemán y al de Asuntos Extranjeros, asi como al Alto Mando de la Armada alemana. Todos ellos tenían diferentes $y$, a veces, opuestos intereses. El principal objetivo del Ministerio de Economía era el de concentrar las actividades económicas, de modo que la economía de guerra pudiera sostener el campo de batalla europeo. El Alto Mando de la Armada peleó contra los objetivos del Ministerio, por temor de perder a México como proveedor importante de combustible y petróleo para la Armada alemana. En medio de este jaloneo de guerra, irrumpió el Ministerio de Asuntos Extranjeros tratando de ejercer una política exterior coherente. " Estos intereses diferentes ocasionaron cuatro largos meses de confusión en las relaciones económicas germanomexicanas.

Dos meses después de haberse declarado la guerra, la confusión había llegado a tal punto que el embajador alemán en México cablegrafió a Berlín:

El resultado de su actitud es el de haber minado el prestigio de la legación alemana respecto a su posición hacia la burocracia mexicana. Será imposible negociar con el ministro de Hacienda, que es el enlace crucial en la cooperación y los proyectos germano-mexicanos, aquí, en México. ${ }^{12}$

Rüdt resaltaba que el comportamiento germano... Se interpreta como resistencia del lado alemán a satisfacer las demandas legales mexicanas. Esto dana severamente la posición y los intereses alemanes en México. Si la situación continúa, México simplemente confiscará los barcos alemanes que están en los puertos mexicanos y los venderá como compensación por los embarques mexicanos de petróleo. ${ }^{13}$

\footnotetext{
9 Reiner Pommerin, Das Dritte Reich und Lateinamerika (1939-1942), Düsseldorf, 1977 , p. 84.

${ }_{10}$ Telegrama núm. 208, Rüdt a AA, 28 de octubre de 1939, en Records of the German Foreign Ministry Archives (en adelante citado GFMA), Handelspolitische Abteilung IX, Nordamerika, México, Petróleo, mayo 1936-julio 1942, microfilm núm. 5749/415 850-8431 (en adelante citado GFMA Ha. Pol).

"Pommerin. op. cit.. p. 84

12 Tel. núm. 253, Rüdt a AA, 21 de noviembre de 1939, en GFMA Ha Pol IX.

13 Tel. núm. 1.70, Rüdt a Ministerio de Economia (RWM), 7 de octubre de 1939, en ibid.
} 
El ministro de Hacienda mexicano estaba todavía esperando una promesa que confirmara las futuras entregas alemanas de artículos pedidos a mediados de noviembre de $1939 .{ }^{14}$ Como para diciembre la cuestión no había cambiado, el ministro mexicano envió finalmente un emisario a Europa y Alemania, el señor Cortina, con el fin de obtener de primera mano una impresión sobre la situación.

Mientras el señor Cortina estaba en camino a Europa, el gobierno alemán reaccionó por fin aclarando el asunto por medio de una disposición oficial que decía que ninguna mercancía más sería embarcada hacia América Latina como resultado del bloqueo británico. $^{15}$

A finales de enero de 1940, el señor Cortina llegó a Berlín. Visitó el Ministerio de Economía alemán y comunicó al asombrado consejero económico que Gran Bretaña y Francia habian convenido en permitir el embarque de artículos alemanes a México a través del bloqueo, si los artículos habian sido ordenados y pagados antes del estallido de la guerra. Declaró que el gobierno mexicano, en lo sucesivo, estaría también interesado en el envío, de la misma forma, de mercancias para México. En tal caso, México estaría dispuesto a correr todo los riesgos de transporte e incluso a hacer un pago del $20 \%$ en efectivo y por adelantado, en todos los nuevos contratos. Los pagos posteriores en efectivo deberian hacerse de acuerdo con el progreso de la producción. ${ }^{16}$ El consejero económico alemán dio al señor Cortina la seguridad de que todos los proyectos planeados y los artículos ordenados serían producidos y embarcados hacia México. ${ }^{17}$

Cuando el emisario mexicano estaba en camino de regreso a México, el Ministerio de Economia alemán revocó dichas seguridades, emitiendo una disposición en el sentido de que, en un futuro cercano, ningún nuevo contrato a corto plazo con países extranjeros podría firmarse. Ningún nuevo material para proyectos de exportación podría ser asignado hasta fines de $1941{ }^{8} \mathrm{El} 7 \mathrm{de}$ febrero de 1940, el gobierno alemán declaró públicamente que no se efectuaría ninguna excepción en cuanto a las exportaciones para América Latina. Todos los contratos existentes con México fueron inmediatamente pospuestos o renegociados para el periodo de la posguerra. ${ }^{19}$ Así, aunque las relaciones económicas entre México y Alemania habian cesado de hecho al estallar la guerra, tomó casi medio año al gobierno alemán poner fin a la confusión y a los choques entre sus ministerios. Al final, la posición del Ministerio de Economía alemán llegó a ser la de la política exterior alemana.

Al investigar el periodo que va del inicio de la segunda guerra mundial a la declaración del gobierno alemán en febrero de 1940 , resulta obvio que el bloqueo británico había sido un pretexto y no la razón verdadera para la cesación del comercio germano-mexi-

14 Tel. núm. 234, Rüdt a AA, 11 de noviembre de 1939 en Ibid.

is Pommerin, op. cit, p. 101.

16 GMFA Ha Pol IX, vid 14 1670/40, memo RWM, I de febrero de 1940.

17 Ihid.

18 Ibid., RWM a AA, 2 de febrero de 1940.

${ }_{19}$ Vid 14/4507 en Ha Pol 1 Xb 47, RWM a AA, 7 de febrero de 1940, en Politisches Archiv des Ausuärtigen Amts, Bonn, West Germany (PA AA). 
cano. Era mucho más atribuible a las propias insuficiencias económicas alemanas, a la falta de preparación para la guerra que surgía, a la ausencia de una clara política de comercio exterior, a las disputas entre las corporaciones involucradas y los ministerios alemanes sobre el sistema de pago, a la rivalidad entre los ministerios. de Economía, Asuntos Extranjeros y el Alto Mando de la Armada sobre la conducción de la política económica extranjera alemana en México y finalmente, a la creciente incapacidad de la economía de guerra alemana para destinar materias primas a productos de exportación.

Sin embargo, hasta 1941, en toda América Latina se presumía que después de la caída de Francia, Alemania podría atacar a Gran Bretaña y conquistarla sin gran dificultad. En estos términos, los politicos mexicanos creían que en semejante escenario de posguerra, Alemania controlaria el enorme mercado de Europa occidental y que éste necesitaría urgentemente materias primas de México. ${ }^{20}$ Por tal motivo, México se mantuvo en una actitud de observación y espera hacia el Tercer Reich, aunque comprometido con los Estados Unidos como resultado de sus necesidades económicas. Desde épocas anteriores, el embajador alemán en México, Rüdt, mantenía una relación amistosa con el ministro de $\mathrm{Ha}$ cienda mexicano, Suárez. Una y otra vez este último había asegurado a Rüdt que México estaba interesado en proveer materias primas a una futura Europa, dominada por Alemania. A cambio, el embajador alemán había prometido reiteradamente al ministro Suárez que el Tercer Reich restablecería sus lazos con México inmediatamente después de la guerra. ${ }^{21}$

Desde febrero de 1940 en adelante, el principal pilar de las relaciones germano-mexicanas cambió de la cooperación económica a las actividades diplomáticas. Después del fracaso de la economia alemana en mantener el mercado mexicano, el principal objetivo de la política germana llegó a ser el de conservar a México al margen de la segunda guerra mundial y alejado de los Estados Unidos. Adicionalmente, los contactos alemanes con México continuarian usándose como una base de propaganda y actividades de sabotaje contra los Estados Unidos. ${ }^{22}$ Con el derrumbe de su mercado europeo, el problema principal para México llegó a ser el de la dependencia económica de su vecino del norte. Los mexicanos no favorecian una colaboración demasiado estrecha e incluso una alianza con los Estados Unidos contra el Eje. Así, los políticos mexicanos intentaron mantener, hasta 1941, tanta distancia como fuera posible con los Estados Unidos, para maniobrar libremente sus intereses nacionales. Enfrentando ambas fuerzas, Alemania y los Estados Unidos, México pudo arreglárselas con éxito para lograr diferentes opciones, en tanto el ganador de la guerra no fuera previsible. De este modo, México y Alemania se usaron mutuamente, por diferentes razones, para influir a favor de sus intereses en los Estados Unidos.

20 GMFA Ha Pol IX, tel. nüm. 226, Rüdt a AA, 11 de mayo de 1940, ibid., tel. núm. 470, Rüdt a AA, 27 de julio de 1940.

21 Ibid.. memo Koppelmann a AA, 27 de junio de 1940.

2Paul Leverkühn, German Military Intelligence, Londres, 1954, p. 202. 
El embajador en México, Rüdt, había apoyado siempre la colaboración con la familia revolucionaria de México, principalmente porque podía garantizar cierto distanciamiento mexicano de los Estados Unidos. ${ }^{23}$ En compensación, los funcionarios mexicanos estaban conscientes de los intereses germanos y trataban de presentarse a sí mismos de la manera que Alemania prefería: críticos y alejados de los poderes aliados. Por ejemplo, el embajador mexicano en los Estados Unidos, Castillo Nájera, dijo al embajador italiano en ese país que "el imperialismo alemán pronto lucharia contra el imperialismo británico. Anteriormente, el imperialismo británico había causado un montón de dificultades a México, cosa que no podía decirse del imperialismo alemán." 24

Hacía hincapié en la intención del gobierno mexicano de permanecer neutral en el conflicto entre el Eje y los Aliados. Es de particular interés examinar el proceder mexicano en la política exterior hacia Alemania y los Estados Unidos y cómo se las arregló para satisfacer las espectativas de ambos países al mismo tiempo. Buen ejemplo de esto es el caso del embajador del gobierno polaco en el exilio en Angers, Francia, a principios de 1940. En mayo de 1940 , el presidente mexicano, Cárdenas, dio públicamente la bienvenida al representante del gobierno. polaco en el exilio, lo reconoció como legítimo representante del pueblo polaco y otorgó a su gobierno una representación diplomática en la ciudad de México. Esto podía ciertamente ser interpretado como una provocación por Alemania, país que había atacado a Polonia en el otoño de 1939. Sin embargo, el mismo día, después de una protesta de la legación alemana contra la acción del presidente, el ministro de Hacienda Suárez visitó al embajador alemán con el fin de aclarar la posición mexicana. Comunicó a Rüdt que México era un país pequeño y que siempre debía estar en guardia contra una invasión (esto es de los Estados Unidos). En consecuencia, México debía pronunciarse contra cualquier clase de invasión, como en el caso polaco. Suárez pidió explícitamente al embajador Rüdt que no diera demasiada importancia a la acción mexicana. ${ }^{25}$

El procedimiento es obvio. El ministro mexicano intentaba excusar el reconocimiento mexicano al representante polaco aludiendo a los Estados Unidos. Así describió la acción del presidente como una protesta indirecta contra cualquier grupo que desde los Estados Unidos aspirara a pasar por alto la integridad territorial de un país más débil o neutral. Para el gobierno de los Estados Unidos, el reconocimiento mexicano aparece como una firme actitud contra el brutal ataque a Polonia por parte de la Alemania nazi. Podia interpretarse como un apoyo mexicano al hemisferio occidental contra los poderes del Eje. Públicamente, México y el Tercer Reich pertenecian a bloques ideológicos opuestos. Extraoficialmente sin embargo, hicieron todo lo posible para

${ }^{23} G M F A$, Head of Auslandsorganisationen Ibero America/Racial Laws, Microfilm nüm. 257/168 723-821, 1937-1940, Ha Pol IX 859, Rüdt a AA, 14 de abril de 1939.

${ }_{24}$ GFMA, Staatssekretār, México, microfilm núm. 176/84707-947, agosto 1939 septiembre 1942 (en adelante citada como St Sek), tel. núm. 141, Rüdt a AA, 22 de septiembre de 1939.

${ }_{25}$ GFMA St Sek, tel. núm. 260, Rüdt a AA, 22 de mayo de 1940. 
restar importancia a todas las diferencias ideológicas, de modo que sus intereses vitales mutuos, a saber, el comercio, el petróleo y el distanciamiento de los Estados Unidos, no se vieran afectados.

En esta intriga, el secretario de Relaciones Exteriores y el presidente mexicano representaban la posición más a favor del hemisferio occidental, mientras que el ministro mexicano de Hacienda se pronunciaba por una política de cooperación euromexicana. Los dos secretarios, el de Hacienda y el de Relaciones Exteriores, no se contradecían en lo que concernía a la política extranjera de México, sino más bien se complementaban, puesto que eran la representación de las dos caras de una misma moneda. Esta política daba a México una gran flexibilidad y le otorgaba espacio para moverse de un lado a otro, entre el apoyo alemán y el de los Estados Unidos, sin causar gran daño.

De ahí en adelante puede observarse que cuando se hacia una declaración oficial relacionada con las potencias del Eje, la legación alemana recibía inmediatamente una interpretación no oficial de la misma, ya sea por medio de conversaciones personales con el ministro Suárez o a través de amigos mutuos de la embajada alemana y de los ministros mexicanos. México jugaba frecuentemente la carta de los Estados Unidos, e hizo todo lo posible para hacer creer a los alemanes cuán dependiente era de su vecino del norte. Siempre el principal argumento era que los Estados Unidos estaban chantajeando a México con una intervención. En los registros publicados por los Estados Unidos, no se puede encontrar ningún documento que pruebe tal amenaza.

Después de la caída de Francia, los Estados Unidos presionaron a México, especialmente en lo relacionado con las actividades alemanas de propaganda que habian aumentado significativamente. El presidente Cárdenas había expresado sus simpatias por la nación francesa y condenado el ataque de la Italia fascista. La prensa mexicana publicó su discurso en primera plana. ${ }^{26}$ Al mismo tiempo, el ministro Suárez visitó la legación alemana, expresando al consejero en economía alemán que contaba con un pronto restablecimiento de las relaciones comerciales entre México y Alemania. Esperaba que México pudiese satisfacer favorablemente las crecientes demandas de materias primas de la futura Europa controlada por Alemania. En general, consideraba positiva la victoria germana sobre Francia y hacía hincapié en que ahora Alemania podría probablemente atacar a Gran Bretaña; con la que México no simpatizaba. En contraste con este desagrado hacia Gran Bretaña, el pueblo mexicano sentía simpatía hacia Alemania. ${ }^{27}$

Debido a las repetidas demandas de la embajada de los Estados Unidos en México para que se pusiera fin a la propaganda alemana, el ministro mexicano de Relaciones Exteriores declaró persona non grata, el 11 de junio de 1940, al agregado de prensa alemán, Dietrich, añadiendo que todas las actividades alemanas de propaganda debian cesar en México inmediatamente. ${ }^{28}$ Dos

${ }^{26}$ Excélsior, México, D.F. 1940, p. 1.

${ }^{27}$ GFMA St Sek, tel. núm. 354, Rüdt a $\mathrm{AA}, 20$ de junio de 1940.

28 Ibid., tel. núm. 333, Rüdt a AA, 14 de junio de 1940. 
dias después, el ministro Suárez era nuevamente huésped de la legación alemana. Pidió comprensión al gobierno alemán respecto al caso del agregado de prensa. Dijo a Rüdt que México tenía que acatar la demanda de los Estados Unidos de expulsar al agregado Dietrich para ayudar a los mexicanos que trabajaban en los Estados Unidos. El ministro Suárez deploraba mucho la acción efectuada contra el agregado de prensa alemán. Ciertamente, estas declaraciones no ratificaban el propósito de la política del "Buen Vecino".

En el otoño de 1940, después de la elección del nuevo presidente mexicano, Avila Camacho, el ministro mexicano de Relaciones Exteriores se acercó a la legación alemana, solicitándole enviara un embajador en misión especial a la ceremonia de toma de posesión en el mes de diciembre siguiente, cosa que el gobierno mexicano apreciaría especialmente. El ministro alemán de Asuntos Extranjeros accedió al deseo a regañadientes, designando en noviembre al ministro Rüdt embajador en misión especial. ${ }^{30}$

Durante la toma de posesión, a la que los Estados Unidos enviaron expresivamente al vicepresidente Wallace, el embajador Rüdt fue reconocido públicamente por el presidente mexicano y tratado extremadamente bien. El periódico Excélsior publicó incluso un artículo especial conteniendo el discurso del embajador alemán y una foto suya colocada exactamente arriba de la del vicepresidente Wallace. Se encomiaba al embajador Rüdt por su excelente discurso pronunciado en español. ${ }^{31}$ Después de las festividades de la toma de posesión, varios funcionarios mexicanos le aseguraron a Rüdt que el presidente Avila Camacho permanecería constante a pesar de las demandas de los Estados Unidos de romper con la influencia alemana. No había razones para preocuparse por el futuro de la colonia germano-mexicana ni por las relaciones entre ambos paises. ${ }^{32}$

La toma de posesión fue un éxito para la posición de la embajada alemana y una provocación para la embajada de los Estados Unidos en México. Sin embargo, el esperado fin de la guerra nó llegaba y el gobierno mexicano dependía más que nunca del mercado norteamericano y de la cooperación con los Estados Unidos. Por tanto, México tenía que acceder a la demanda de solidaridad hemisférica y unirse a la política de los Estados Unidos para el hemisferio occidental. Así la prensa mexicana se volvió completamente anti Tercer Reich; el presidente Avila Camacho subrayó en su discurso del Día Panamericano que ningún poder debía basarse en las bayonetas fascistas y, finalmente, en abril de 1941, México y otros países latinoamericanos embargaron todos los barcos alemanes que se hallaban en sus puertos. ${ }^{33}$

Después del èmbargo de las embarcaciones, el embajador Rüdt

${ }^{24}$ Ibid.

31) Ibid. tel. núm. 682. Rüdt a AA, 31 de octubre de 1940.

${ }^{31}$ Excélsior, 2 y 4 de diciembre de 1940.

${ }^{32}$ GFMA St Sek, tel. núm. 766, Rüdt a AA, 6 de diciembre de 1940.

33 Para una detallada descripción del acercamiento de México a los Estados Unidos ver: Blanca Torres Ramírez, Historia de la revolución mexicana. Periodo 19401952. 19. México en la segunda Guerra Mundial, México, El Colegio de México, 1979. vol. 20. 
tuvo la oportunidad de discutir con el presidente Avila Camacho el estado de las relaciones germano-mexicanas. En esta conversación, el embajador Rüdt se quejó de las medidas tomadas, en especial del embargo de los barcos que, según él, contradecía las seguridades previamente otorgadas. A los ojos del gobierno alemán, los ataques de Avila Camacho a su pais sólo podian interpretarse como actos hostiles al Tercer Reich. Después de expresar sus quejas. Rüdt se tornó más conciliatorio y expresó su simpatía por México considerando la fuerte presión que los Estados Unidos ejercian sobre el pais.

El presidente Avila Camacho replicó en forma amistosa y pidió su comprensión en el caso del embargo de los buques. Dijo a Rüdt que México había actuado así solamente para prevenir una amenaza de incautación de los barcos por parte de los Estados Unidos, que habian planeado usarlos para abastecer a la flota británica en el Atlántico. En realidad, hizo hincapié en que México no tenia el menor interés en los barcos germanos. Aseguró al embajador alemán que Alemania recibiria desde luego una compensación después de la guerra. Terminó la entrevista asegurándole que México permanecería neutral, aun en el caso de que los Estados Unidos entraran en la guerra. La colonia alemana no tendría nada que temer. Con el fin de ayudar al gobierno mexicano a mantener su posición respecto a los Estados Unidos, pidió a Rüdt que finiquitara todas las actividades que pudieran obrar en descrédito de la presencia de los alemanes en México. ${ }^{34}$ Más tarde, un juez confirmó en Veracruz la indiferente actitud de México respecto a los barcos germanos. Dijo a Rüdt que la devolución de los barcos dependería del resultado de la guerra. Si Alemania ganaba, ganaría también los barcos; si la perdía, los perdería también. ${ }^{35}$ El ataque a Rusia y la consiguiente derrota alemana puso fin a todas las especulaciones mexicanas sobre una rápida terminación de la guerra y una posible victoria del Tercer Reich.

Después de examinar la actitud mexicana hacia el Tercer Reich durante la segunda guerra mundial, paso a examinar la actitud y el interés alemanes en México. El gobierno alemán dejó la conducción de su política mexicana casi enteramente en manos de su embajador, quien durante la guerra intentó conservar vivas y con el menor daño posible las relaciones germano-mexicanas. En parte, el ministro alemán, encargado de los Asuntos Extranjeros, se involucraba en estas relaciones cuando peligraban seriamente, principalmente debido a las actividades germanas.

El problema más difícil para el embajador Rüdt era el de encontrar en Berlín comprensión para las posturas y políticas mexicanas. Las particularidades de la política mexicana eran a menudo extrañas o retorcidas a ojos de la Wilhelmstrasse y de otros ministerios involucrados. Con los años, el embajador Rüdt adoptó una postura pro México y llegó a ser casi abogado de este país y de sus gobiernos.

En general, se oponia a cualquier cosa que interfiriera en la conducción tranquila y discreta de las relaciones diplomáticas ger-

34 GFMA St Sek, tel. núm. 222, Rüdt a AA, 4 de abril de 1941.

35 ibid. tel. núm. 244. Rüdt a Ha Pol, 9 de abril de 1941. 
mano-mexicanas. En Alemania, Rüdt recibió gran apoyo del Alto Mando de la Armada alemana debido a su experiencia con la industria mexicana del petróleo. Sus conocimientos lo hicieron irremplazable para el puesto y le permitieron tomar una actitud firme frente a la policía secreta y sus planes alemanes de sabotaje o espionaje en México. ${ }^{36}$

Desde el momento en que resultó obvio que las relaciones económicas se habían roto, Rüdt trató de mantener una imagen positiva de la economía alemana en México. Hizo visitas de buena voluntad a ministerios y agencias, describiendo con brillantes colores un supuesto comercio de posguerra. Tan importante era para el Tercer Reich mantener a los Estados Unidos fuera de la guerra como mantener débil la solidaridad hemisférica. Así, la presencia alemana no daria pretexto para que los Estados Unidos entrasen en la guerra ni forzaría deliberadamente a México a tomar partido por los Estados Unidos. Estos objetivos predeterminaron por completo el carácter de las actividades alemanas en México que sólo podian ser de naturaleza defensiva.

No es sorprendente, pues, que el embajador alemán prefiriera la diplomacia silenciosa. Sin ningún convenio posible entre manos, la embajada alemana observaba la declinación de su influencia y el acercamiento de México a los Estados Unidos. La actitud defensiva llegó tan lejos que Rüdt disolvió voluntariamente la rama mexicana del Partido Nacional Socialista Alemán en abril de $1941 .^{37}$

Tanto daño hicieron a las relaciones germano-mexicanas la presión de los Estados Unidos como las acciones del Tercer Reich. En general, el Ministerio de Asuntos Extranjeros alemán rehusó dar a las relaciones germano-mexicanas la misma importancia que les daba el gobierno mexicano. Es más, en general los políticos del Reich trataban a México como un pais del hemisferio occidental alineado a los Estados Unidos. Esto se hizo evidente por primera vez a principios de abril de 1941, cuando el ministro alemán de Asuntos Extranjeros rehusó conceder visa a un diplomático mexicano que habia planeado visitar Vichy, Francia. La negativa ocasionó una protesta inmediata del gobierno mexicano. Este hizo hincapié en que las relaciones germano-mexicanas dependian de un mutuo toma y daca. De no ser así, el gobierno mexicano revaluaría su actitud hacia Alemania. ${ }^{38}$

El tono cortante y acerbo de la nota tuvo el efecto deseado. El embajador Rüdt urgió al Ministerio de Asuntos Extranjeros alemán a reconsiderar su política hacia México. Una y otra vez advirtió que si las actitud germana no cambiaba pronto, se podían esperar pérdidas vitales para la posición alemana. Ello podía afectar la posición total de Alemania en América Latina. Si México se perdía para los intereses alemanes, un eslabón crucial en la información que iba de los Estados Unidos a Alemania, podría perderse también. ${ }^{39}$

36 L. E. Hill, Die Weizsäckerpapiere, Frankfurt, 1974, p. 210.

${ }^{37}$ GFMA St Sek, tel. núm. 182, Rūdt a Bohle, 4 de abril de 1941.

${ }^{38}$ GFMA St Sek, tel. núm. 182, Rüdt a AA, 5 de abril de 1941.

34 Ibid. 
El embajador Rüdt estaba indudablemente en lo cierto. Si la política alemana requería mantener a México distante de los Estados Unidos, su política exterior no podía en absoluto darse el lujo de atacar los intereses de México en Europa.

En el otoño de 1941 se agregó mayor daño a las relaciones. Incluso antes del ataque alemán a Rusia, los Estados Unidos habian cerrado los consulados alemanes en su país, sobre la base de que ya no ejercian sus tareas normales sino antes bien algunas que iban más allá de su responsabilidad. ${ }^{40}$ El Departamento de Estado de los Estados Unidos urgió a los países latinoamericanos a que siguieran su ejemplo.

En represalia por la acción de los Estados Unidos, el Ministerio de Asuntos Extranjeros alemán revocó el exequatur a los Estados Unidos y a los países de América Latina en Alemania y en los territorios ocupados. Así, incluso México tuvo que cerrar sus consulados, a pesar de que su gobierno no había seguido las recomendaciones de los Estados Unidos y habia dejado abiertos los consulados alemanes en México. La acción germana suponía una fuerte desatención respecto a la premisa mexicana de concesiones mutuas. No es sorprendente, pues, que México revocara inmediatamente el exequatur a los consulados germanos en México y enviara al personal de regreso a Europa. 4 Tres días más tarde, el Ministerio de Asuntos Extranjeros alemán comprendió su error y envió una nota a México disculpándose por tal acción y describiéndola como una equivocación. ${ }^{42}$ Sin embargo, el gobierno mexicano no cambió su decisión y el Tercer Reich perdió una influencia significativa y fuentes de información en México.

Con este paso, el gobierno mexicano, mató con buenos resultados dos pájaros de un tiro: mostró al gobierno alemán sus límites, a la par que indirectamente accedía a la solicitud de los Estados Unidos de cerrar los consulados alemanes y se comportaba, según sé esperaba, como un buen vecino.

Razón adicional para la pérdida de la posición alemana era la falta de apoyo de sus propios ministerios a la embajada alemana. Debido a la situación de guerra, habia menos fondos disponibles para propaganda y el Ministerio de Propaganda dejó a la legación alemana en México sin instrucciones. Además, cartas o peticiones urgentes e importantes de la legación alemana permanecieron sin respuesta, por lo que el embajador alemán advirtió a Berlín:

Tres pedidos de emergencia para finanzas extraoficiales para prensa y propaganda no han tenido respuesta todavia. Le urjo a cambiar de actitud. A causa de la carencia de fondos, estamos perdiendo un periódico tras otro, que intereses hostiles compran ahora. Seria un error trágico pensar que es posible persuadir a los periodistas mexicanos con unos pocos regalos o con información personal. En este pais, los periodistas esperan principalmente efectivo y ganancia. Por lo visto (es decir, los Estados Unidos) parece comprender mejor el asunto y provee a los periodistas mexicanos con mayor éxito que nosotros. Por favor

${ }^{40}$ Ibid., tel. núm. 563, Rüdt a AA, 28 de agosto de 1941.

4 Ibid., tel. núm. 555, Rüdt a AA, 23 de agosto de 1941.

42 Ibid., tel. núm. 560, Weizsäcker a Rüdt, 26 de agosto de 1941. 
conteste inmediatamente para que ulteriores beneficios. no se pierdan en lo sucesivo. ${ }^{43}$

A pesar de esta carta y de quejas posteriores, la actitud de Berlin no cambió, contribuyendo a la declinación de la posición alemana en México.

Finalmente, tiene particular interés saber si el gobierno nazi intervino en los asuntos politicos internos de México y cómo lo hizo. ¿Explotó el Tercer Reich la tensa atmósfera que rodeó las elecciones mexicanas de 1940 para sus propósitos? A más de esto, es interesante ver si existió un segundo despacho Zimmermann y en que forma una quinta columna alemana tuvo algún papel en México durante la segunda guerra mundial. ${ }^{4}$

Además de su interés económico en México, y en especial desde el estallido de la segunda guerra mundial, Alemania vio a México como una base para su propaganda antiestadunidense, explotando el temor mexicano al "imperialismo yanqui". Así, la propaganda tenia una tarea triple: ganar el favor de los mexicanos hacia los puntos de vista del Tercer Reich con respecto a la política alemana; conservar a México alejado de los Estados Unidos y al hemisferio occidental débil y, finalmente, apoyar la neutralidad de América Latina en la guerra.

Antes y durante la guerra, el Deutsche Nachrichtenbüro y otras agencias de noticias del Tercer Reich proporcionaron a la prensa mexicana articulos que presentaban los asuntos internacionales desde el punto de vista nazi. Aunque la propaganda en la prensa había tenido bastante éxito antes de la guerra, ${ }^{45}$ la propaganda alemana experimentó un retroceso decisivo cuando el agregado de prensa alemán, señor Dietrich, fue declarado persona non grata en México, en junio de 1940 . $^{46}$ También, como se ha descrito antes, la falta de fondos debilitô las actividades alemanas y cada vez más periódicos mexicanos se inclinaban hacia la propaganda a favor de las fuerzas aliadas. Ya desde mayo de 1940, el embajador Rüdt habia cablegrafiado a Berlín que la propaganda aliada estaba apoderándose de las anteriores posiciones germanas.

Desde el ataque alemán a Rusia y en adelante, la embajada alemana y su propaganda perdió toda influencia. Rüdt cablegrafió a Berlin:

Alemania es acusada de asesinato, subversión, actividades policiacas y espionaje en México. Los artículos de nuestras agencias de noticias ya no se publican y las noticias sobre Alemania llegan a México solamente a través de noticieros, películas y documentación de las potencias aliadas. ${ }^{47}$

\$3 Ibid., tel. núm. 207, Rüdt a AA, 7 de mayo de 1940

44 Alton Frye, Nazi Germany and the American hemisphere (1933-1941), Nueva Haven, 1967 , p. 26-28.

+5 Betty Kirk, op. cit.. p. 65.

to Ver nota nüm. 28.

47 GFMA, Bureau ReichsauBenminister 5 México, sin catalogar, abril 1936 junio 1942; tel. núm. 703. Rüdt a $\mathrm{AA}, 28$ de octubre de 1941. 


\section{Conclusión}

La relación entre Alemania y México durante la segunda guerra mundial se basaba solamente en intereses económicos. La exportación de maquinaria y artículos manufacturados alemanes, para proyectos del gobierno mexicano, cesaron con el inicio de la segunda guerra mundial. Contra la opinión formal existente, las exportaciones alemanas a México no cesaron por el bloqueo británico, sino más bien por la incapacidad alemana para resolver los problemas domésticos resultantes de una industria de guerra y su impacto en las compañías y agencias involucradas.

La relación política entre México y el Tercer Reich continuó después de la interrupción de las relaciones económicas; principalmente debido al hecho de que, hasta junio de 1941, México anticipaba la victoria final de Alemania en Europa, país que controlaría entonces un próspero mercado europeo occidental, necesitado de materias primas mexicanas. Cuando estuvo claro que estas expectativas no se cumplirían, México no dudó en volverse hacia los Estados Unidos para entablar una cooperación cercana tanto económica como política. Esta cooperación había sido preparada de manera tentativa desde el estallido de la segunda guerra mundial y siguió en adelante.

La relación política mexicano-germana tenía dos caras. Una pública, según la cual México se oponía oficialmente a la Alemania nazi, y otra extraoficial, por medio de la cual la postura mexicana hacia la Alemania nazi era mucho más abierta y cooperativa de lo que la actitud pública hubiera permitido. Hasta junio de 1941, México era mucho más un vecino ambiguo que un buen vecino para los Estados Unidos y su política de defensa y solidaridad hemisférica.

La actitud política alemana hacia México estaba sustentada en la intención de apaciguar a los Estados Unidos y de mantener débil la solidaridad hemisférica. Sin embargo, las relaciones germano-mexicanas declinaron hasta extinguirse en mayo de 1942 , sin ninguna resistencia o acción del lado alemán, que silenciosamente las dejó decaer. 